\section{Plasmapheresis for the Treatment of Idiopathic Pulmonary Fibrosis}

\author{
Valerii A. Voinov*, Michail M. Ilkovich, Lyubov N. Novikova, \\ Konstantin S. Karchevsky, Oleg V. Isaulov, Daly V. Dzadzua \\ and Anna S. Zacharova
}

Pulmonology clinic, Pavlov First State Petersburg State Medical University, Saint-Petersburg, Russia

\begin{abstract}
Idiopathic Pulmonary Fibrosis (IPF) is a fairly severe autoimmune disease with progressive fatal lung disease, the treatment of which is still not effective enough. Plasmapheresis courses, removing up to 2,5-3,2 I of plasma, was included in a complex treatment of IPF of 52 patients. It was significant reducing of immunoglobulin's, circulating immune complexes and proinflammatory cytokines with improvement of clinical signs. Instead of this in control group (25 patients) effect of convention therapy was little and this disease progressed.

Keywords: Autoimmunity; Idiopathic pulmonary fibrosis; Plasmapheresis
\end{abstract}

\section{Introduction}

This disease of unknown nature, often occurring with autoimmune disorders, refers to the idiopathic interstitial pneumonias. It is characterized by an isolated lesion of the lungs (Idiopathic Pulmonary Fibrosis or IPF) or in the form of pulmonary syndrome in other, usually systemic, diseases (systemic vasculitis, granulomatosis, rheumatoid polyarthritis, systemic lupus erythematosus, etc.). IPF occurs in 9.041.8 per 100,000 population, and worldwide in about 3 million people with a significant increase in the number of cases in recent years [1-3].

\section{Pathogenesis of IPF}

It is supposed that as a result of influence of unknown still etiological factor of the exo or endogenous nature there is an initial damage of alveolar structures (both an endothelium of vessels and alveolocytis) to development of interstitial edema.

These processes are followed by attraction of alveolar macrophages, neutrophils, lymphocytes with an infiltration them alveolar

*Corresponding author: Valerii A. Voinov,Pulmonology clinic, Pavlov First State Petersburg State Medical University, Saint-Petersburg, Russia, Tel: +7-9119126502; Email: voinof@mail.ru

Citation: Voinov VA, Ilkovich MM, Novikova LN, Karchevsky KS, Isaulov OV, et al.(2019) Plasmapheresis for the Treatment of Idiopathic Pulmonary Fibrosis. J Pulm Med Respir Res 5: 025.

Received: May 20, 2019; Accepted: July 05, 2019; Published: July 12, 2019

Copyright: () 2019 Voinov VA, et al. This is an open-access article distributed under the terms of the Creative Commons Attribution License, which permits unrestricted use, distribution, and reproduction in any medium, provided the original author and source are credited. partitions that defines a stage of an alveolitis. Activation of T-helpers promotes allocation of the cytokines of the Th-2 type (interleukins 4, $5,10,13)$ stimulating proliferation of fibroblast and processes of a fibrosing $[4,5]$. The excited macrophages and neutrophils are sources of proteolytic enzymes that finally the interstitium conducts to hyper production of collagen and formation of pulmonary fibrosis. The fibrosing alveolitis is a characteristic sign substantial increase of level of the circulasting immune complexes (CIC), immunoglobulins A, G and $\mathrm{M}$, antipulmonary autoantibodies against the increased proteolytic activity of blood [4]. IPF are quite often combined with cardiovascular diseases, a gastro-oesophageal reflux, pulmonary hypertension, an obstructive sleep apnoea, that ultimately lead to disease progression and death $[6,7]$.

The illness proceeds extremely severe, is followed by the increasing respiratory insufficiency and comes to an end with a lethal outcome within 2-3 years from the moment of emergence of the first symptoms [8-11]. As the illness develops gradually and with indistinct symptoms, it is late diagnosed and patients during rather long time don't receive treatment [12]. The analysis of deadly outcomes at group of children with the same chronic interstitial pulmonary diseases showed that opportunity to live 24,48 and 60 months had $83 \%$, $72 \%$ or $64 \%$ of these children respectively [13].

\section{Drug Therapy of IPF}

Considering autoimmune character of a disease corticosteroids and cytostatics find application, however many authors consider them dangerous and don't recommend them $[14,15]$. However, such therapy does not lack a large number of adverse reactions. Corticosteroids cause Cushingoid syndrome and hypertriglyceridemia, which predisposes to mitochondrial dysfunction and damage to cardiomyocytes, accompanied by free radicals generation [16]. Steroid therapy predisposes to the development of diabetes mellitus, especially in older patients with pre-diabetes mellitus, exacerbating vascular disorders [17]. Moreover, there are certificates on higher risk of development of lung cancer at this disease which isn't depending even on the smoking fact [18], that it is possible to connect also with deeper immunosuppression during glucocorticoid therapy.

As the fibrosing is the main process in formation of all group of these diseases, also antifibrotic preparations, such as pirfenidon and nintedanib are used [19-21]. However they render only temporary medical effect at an mild to moderate forms of diseases, and in severe form they not only inefficient, but also are toxic [22]. In particular, they have high hepato-gastrointestinal toxicity [23], skin phototoxic reactions, up to a leukomelanoderma [24-26]. Besides, neither nintedanib, nor pirfenidon not at all patients prevent progressing of fibrosis $[27,28]$. Thus it is necessary to use only on a long-term oxygen therapy and overall lung transplantation [27]. Besides, it is necessary to consider also rather high cost of such treatment- from 1000 to 2700 Euro a month.

\section{Plasmapheresis in the Treatment of IPF}

It is difficult to expect essential return development of already come organic damages of lungs, in particular fibrosis, however 
Citation: Voinov VA, Ilkovich MM, Novikova LN, Karchevsky KS, Isaulov OV, et al.(2019) Plasmapheresis for the Treatment of Idiopathic Pulmonary Fibrosis. J Pulm Med Respir Res 5: 025

impact on initial stages of a disease is quite possible- alveolitis and interstitial swelled. At removal from an organism as primary agents, toxic for alveolar structures, and, obviously, by-products of the immune response it is possible to expect an improvement or, at least, stabilization of pathological processes in the lungs parenchyma. Nevertheless, such approach is used only at development of a pulmonary fibrosis against other autoimmune diseases, such as ANCA-vasculitis or microscopic angiitis [29,30], and also at a acute exacerbations of a fibrosing alveolitis in cases of inefficiency of usual glucocorticoid therapy [31].

\section{Our Own Observations}

In our clinic a plasma exchange at the fibrosing alveolitis began to be applied since 1986. Studied patients with IPF were divided into 2 groups: the main and comparative. The main group included 52 patients, and the control group was made by 25 patients. At 52 surveyed patients with a group basis treatment was carried out by basic drugs (corticosteroids) and PA. 25 patients of comparative group received only corticosteroids. Efficiency of carried-out therapy in both groups estimated on the basis of dynamics of clinical and immunological indicators. As markers of activity of an inflammation the following indicators were used: circulating immune complexes (CIC) (there levels were measured using nephelometric method in polyethylene glycol precipitation reaction). Pro-inflammatory (IL-1 $\beta$, IL-2, IFN $\gamma$ ) and anti-inflammatory (IL-ra, IL-10) cytokines (test systems of the Protein CounterCompany, St. Petersburg), in peripheral blood serum of patients with IPF were investigated before and after each course PA and in 6 months after it.

Besides, indicators of function of external breath, in particular the vital lung capacity (VLC), were investigated. The diagnosis was made collectively (multidisciplinary approach) with participation of pulmonologists and radiation diagnostics specialists. Patients with pulmonary fibrosis included both their idiopathic forms, as well as those arising against the background of other systemic autoimmune diseases (lupus, rheumatoid arthritis, scleroderma).

The patient of the main group conducted courses PA (4 sessions with intervals 2 days with removal of 700-900 $\mathrm{ml}$ of plasma and the general removal it up to 1-1.5 of circulating plasma volumes). Repeated courses PA were performed in 6-12 months [32]. Efficiency of carried-out therapy in both groups estimated on the basis of dynamics of clinical and immunological indicators. All the studied patients were selected randomly, but considering their comparability by the disease severity and the drug therapy type. All of them were observed for a year.

\section{Results}

Dynamics of levels of the CIC is presented in table 1, and shifts of various cytokines are visible in table 2 .

Table 1 shows that after 6 months, of course, there is a rise in the CIC content, but it does not reach the previous level. The same trend continues in the next 6 months. All this can significantly increase the life expectancy of such patients with even lower levels of drug support.

Thus levels and such toxic cytokine as TNF- $\alpha$, IL-2, and IFN- $\gamma$ (Table 2) decreased also. However the maintenance of IL-10 increased, but it also was positive shift as this cytokine oppresses activation of macrophages and inhibits production of cytokines by
Th-1 lymphocytes. And, these shifts remained even in 6 months after the plasmapheresis course, especially it concerns level of INF- $\gamma$.

\begin{tabular}{|c|c|c|c|}
\hline Plasmapheresis courses & The $1^{\text {st }}$ course & In 6 months & In a year \\
\hline Before course & $252.3 \pm 12.2$ & $221.2 \pm 12,5$ & $198.8 \pm 10.3$ \\
\hline After course & $140.2 \pm 9.3^{*}$ & $131.4 \pm 8.3^{*}$ & $126.1 \pm 7.8^{*}$ \\
\hline
\end{tabular}

*changes from initial level are reliable $(\mathrm{p}<0.05)$

Table 1: Amount of circulating immune complexes in consistent courses of plasmapheresis $(n=52)$.

\begin{tabular}{|c|c|c|c|c|}
\hline Stages & $\begin{array}{c}\text { TNF- } \alpha \\
\text { picogram } / \mathrm{ml}\end{array}$ & $\begin{array}{c}\text { INF- } \gamma \\
\text { picogram } / \mathrm{ml}\end{array}$ & $\begin{array}{c}\text { IL-10 } \\
\text { picogram } / \mathrm{ml}\end{array}$ & $\begin{array}{c}\mathrm{IL}-2 \\
\text { picogram } / \mathrm{m}\end{array}$ \\
\hline Before plasmapheresis & $35.3 \pm 3.36$ & $103 \pm 8.45$ & $16.2 \pm 1.97$ & $45.6 \pm 3.6$ \\
\hline After plasmapheresis & $28.2 \pm 2.21 *$ & $41.5 \pm 3.98^{*}$ & $23.2 \pm 1.73^{*}$ & $40.3 \pm 3.6$ \\
\hline In 6 months & $29.85 \pm 2.32$ & $77.48 \pm 5.4 *$ & $17.25 \pm 1.3$ & $42.2 \pm 3.7$ \\
\hline
\end{tabular}

Table 2: Cytokines levels in the course of a plasma exchange $(n=52)$.

The same can be told also about the vital capacity of lungs (Table $3)$. It is visible that in the course of a plasmapheresis there is an opportunity significantly to restore the vital capacity of lungs while only at medicamentous therapy of it practically doesn't occur.

\begin{tabular}{|c|c|c|}
\hline Groups & Before treatment & In 6 months \\
\hline Main $(\mathrm{n}=52)$ & $58.82 \pm 1.3$ & $65.13 \pm 2.4^{*}$ \\
\hline Control $(\mathrm{n}=25)$ & $55.27 \pm 2.5$ & $59.65 \pm 1.2$ \\
\hline *changes from initial level are reliable $(\mathrm{p}<0.05)$
\end{tabular}

Table 3: Dynamics of vital lungs capacity values ( $\% \%$ of due level).

It is followed also by gas exchange improvement that is visible on increase of $\mathrm{PaO} 2$ after a plasmapheresis, keeping and after the subsequent courses of treatment while in control group there is only its insignificant stabilization (Table 4).

\begin{tabular}{|c|c|c|l|}
\hline Groups & Before treatment & In 6 months & In the next 6 months \\
\hline Main $(\mathrm{n}=52)$ & $69.81 \pm 2.3$ & $73.34 \pm 3.9$ & $75.62 \pm 2.1^{*}$ \\
\hline Control $(\mathrm{n}=25)$ & $70.22 \pm 6.4$ & $70.83 \pm 4.8$ & $70.63 \pm 5.8$ \\
\hline *changes from initial level are reliable $(\mathrm{p}<0.05)$ \\
\hline
\end{tabular}

Table 4: The level of $\mathrm{PaO} 2$ during courses of plasmapheresis (mm of mercury).

\section{Discussion}

The results given above show that tactics accepted at us - plasma exchange courses ( 4 sessions with the full removal of plasma in volume of 1-1,5 CPV) with intervals between them of half a year lead to increase of the $\mathrm{PaO} 2$ level, stabilization of vital capacity of lungs which without this treatment tend to the permanent and progressing decrease. It allows to reduce doses of steroid preparations by $40 \%$ and almost completely to avoid purpose of cytostatics that in due time prevents aggravations and keeps the acceptable quality of life and even working capacity of patients within 7-15 years.

Thus it is necessary to consider that decrease in a dose of hormonal preparations can reduce also risk of accession of oncological 
Citation: Voinov VA, Ilkovich MM, Novikova LN, Karchevsky KS, Isaulov OV, et al.(2019) Plasmapheresis for the Treatment of Idiopathic Pulmonary Fibrosis. J Pulm Med Respir Res 5: 025.

diseases which meet at patients with a fibrosing alveolitis considerably more often than in the general population, and even bigger frequency, than at smokers [33]. In our previous studies it has already been established that the general life expectancy of these patients significantly increases- from $5.3 \pm 0.5$ years at the isolated medicamentous therapy, to $9.3 \pm 1.1$ years at the complex therapy including a plasma exchange $[4,5,34]$.

Improvement of health of patients, though short-term is even surprising, at far come organic damages of lungs, speaking about existence and at a stage of fibrosis of some functional deteriorations. It is, obviously, about the accompanying edema of alveolar partitions of toxic genesis demanding a detoxification.

When fibrosing alveolitis proceeds against the other collagenosis manifestations, distinct clinical improvement is noted and these accompanying symptoms - characteristic skin deteriorations are softened at systemic lupus erythematosus, pains and constraint in a body disappear, mobility of joints at rheumatoid polyarthritis improves, progressing of organic disorders in joints is slowed down.

\section{Conclusion}

Thus, by means of plasmapheresis it is possible to suppress autoimmune processes and to hold a condition of steadier remission at much smaller level of corticosteroids. It is probably connected with decrease in activity both cellular and humoral immunity when carrying out of plasmapheresis and stimulation of anti-inflammatory mechanisms.

Results of work convincingly show considerably the best results of treatment of IPF at the initial stages of a disease. And it is valid, difficult to expect essential return development of already come organic lesions of lungs, in particular fibrosis, impact on initial stages of a disease- alveolitis and interstitial edema is however quite possible. At removal from an organism as primary, and, obviously, by-products of the immune answer it is possible to hope on improvement or stabilization of pathological processes in a parenchyma of lungs.

Experience of the last year's shows adverse effects of longer intervals between courses of plasmapheresis when severity of a disease again increased. Considering preservation of positive results of treatment within 6 months, obviously it is necessary to recommend to such patients regular passing of courses of plasmapheresis in each half a year.

\section{References}

1. Hutchinson J, Fogarty A, Hubbard R, McKeever T (2015) Global incidence and mortality of idiopathic pulmonary fibrosis: a systematic review. Eur Respir J 46: 795-806.

2. Hopkins RB, Burke N, Fell C, Dion G, Kolb M (2016) Epidemiology and survival of idiopathic pulmonary fibrosis from national data in Canada. Eur Respir J 48: 187-195.

3. Martinez FJ, Collard HR, Pardo A, Raghu G, Richeldi L, et al. (2017) Idiopathic pulmonary fibrosis. Nat Rev Dis Primers 3: 17074

4. Ilkovich MM, Novikova LN, Dvorakovskaya IV, luchkevich VS (2011) Idiopathic fibrosing alveolitis. in.: Disseminated lung diseases. Edited by M.M. Ilkovich. Moscow: GEOTAR-Media: 24-83.

5. Ilkovich MM, Novikova LN, Ilkovich YM (2016) Interstitial and orphan lung diseases. Edited by M.M. Ilkovich. Moscow:GEOTAR-Media: 39110
6. Raghu G, Amatto VC, Behr J, Stowasser S (2015) Comorbidities in idiopathic pulmonary fibrosis patients: a systematic literature review. Eur Respir J 46: 1113-1130.

7. Margaritopoulos GA, Antoniou KM, Wells AU (2017) Comorbidities in interstitial lung disease. Eur Respir Rev 26: 160027.

8. Baroke E, Gauldie J, Kolb M (2013) New treatment and markers of prognosis for idiopathic pulmonary fibrosis: lessons learned from translational research. Expert Rev Respir Med 7: 465-478.

9. Chakraborty S, Chopta P, Ambi SV, Dastidar SG, Ray A (2014) Emerging therapeutic interventions for idiopathic pulmonary fibrosis. Expert Opin Investig Drugs 23: 893-910.

10. Cushing L,Kuang P, Lü J (2014) The role of miR-29 in pulmonary fibrosis. Biochem Cell Biol 93: 109-118.

11. Xaubert A, Ancochea J, Molina-Molina M (2017) Idiopathic pulmonary fibrosis. Med Clin (Barc) 148: 170-175.

12. Mazzoccoli G, Carughi S, De Cata A, Giuliani A, Masciale N, et al. (2003) Interstitial lung disease. Recenti Prog Med 94: 227-237.

13. Fan LL, Kozinetz CA (1997) Factors influencing survival in children with chronic interstitial lung disease. Am J Respir Cri Care Med 156: 939-942.

14. Behr J (2012) Idiopathic pulmonary fibrosis: modern guideline-concordant diagnostics and innovative treatment Dtsch Med Wochenschr 137: 601604 .

15. Petitpierre N, Beigelman C, Letovanec I, Nicod LP, Lazor R (2014) Idiopathic pulmonary fibrosis: recent diagnostic and therapeutic advances. Rev Med Suisse 10: 2212-2213.

16. Puthanveetil P, Rodrigues B (2013) Glucocorticoid exsess induces accumulation of cardiac glycogen and triglyceride: suggested role for AMPK. Curr Pharm Des 19: 4818-4830.

17. Rogers MAM, Lin P, Nallamothu BK, Kim C, Waljee AK (2018) Longitudinal study of short-term corticosteroid use by working-age adults with diabetes mellitus: risks and mitigating factors. J Diabetes 10: 546-555.

18. Harris JM, Johnston ID, Rudd R, Taylor AJ, Cullinan P (2010) Cryptogenic fibrosing alveolitis and lung cancer: the BTS study. Thorax 65: 70-76.

19. Cottin V (2013) Interstitial lung disease. Eur Respir Rev 22: 26-32.

20. Mazzei ME, Richeldi L, Collard HR (2015) Nintedanib in the treatment of idiopathyc pulmonary fobrosis. Ther Adv Respir Dis 9: 121-129.

21. Rochat T, Charbonnier F, Plojoux J (2015) New therapeutic approaches in 2014 in pulmonary medicine: COPD, asthma and lung fibrosis. Rev Med Suisse 11: 129-132.

22. Israël-Biet D, Juvin K, Dang Tran K, Badia A, Cazes A, et al. (2014) Idiopathic pulmonary fibrosis: diagnosis and treatment in 2013. Rev Pneumol Clin 70: 108-117.

23. Galli JA, Pandya A, Vega-Olivo M, Dass C, Zhao H (2017) Pirfenidone and nintedanib for pulmonary fibrosis in clinical practice: Tolerability and adverse drug reactions. Respirology 22: 1171-1178.

24. Papakonstantinou E, Prasse A, Schacht V, Kapp A, Raap U (2016) Pirfenidone-induced severe phototoxic reaction in a patient with idiopathic lung fibrosis. J Eur Acad DermatolVenerol 30: 1354-1356.

25. Reinholz M, Eder I, Przybilla B, Schauber J, Wollenberg A, et al. (2016) Photoallergic contact dermatitis due to treatment of pulmonary fibrosis with pirfenidone. J Eur Acad Dermatol Venerol30: 370-371.

26. Jeldres A, Labarca G (2017) Is pirfenidone effective for idiopathic pulmonary fibrosis? Medwave 17: e6843.

27. Kreuter M, Bonella F, Wijsenbeek M, Maher TM, Spagnolo P (2015) Pharmacological treatment of idiopathic pulmonary fibrosis: current approaches, unsolved issues, and future perspectives. Biomed Res Int: 329481. 
Citation: Voinov VA, Ilkovich MM, Novikova LN, Karchevsky KS, Isaulov OV, et al.(2019) Plasmapheresis for the Treatment of Idiopathic Pulmonary Fibrosis. J Pulm Med Respir Res 5: 025.

- Page 4 of 5 -

28. Bando M, Yamauchi H, Ogura T, Taniguchi H, Watanabe K, et al. (2016) Clinical experience of the long-term use of piefenidone for idiopathic pulmonary fibrosis. Intern Med 55: 443-448.

29. Collins CE, Quismorio FP Jr. (2005) Pulmonary involvement in microscopic polyangiitis. Curr Opin Pulm Med 11: 447-451.

30. Homma S, Suzuki A, Sato K (2013) Pulmonary involvement in ANCA-associated vasculitis from the view of the pulmonologist. Clin Exp Nephrol 17: $667-671$.

31. Donahoe M, Valentine VG, Chien N, Gibson KF, Raval JS, et al. (2015) Autoantibody-targeted treatments for acute exacerbations of idiopathic pulmonary fibrosis. PLoS One 10: e0127771.
32. Voinov VA (2016) Therapeutic apheresis. Constanţa, Celebris

33. Hubbard R, Venn A, Lewis S, Britton J (2000) Lung cancer and cryptogenic fibrosing alveolitis. A population-based cohort study. Amer J Respir Crit Care Med 161: 646-664.

34. Voinov VA, Ilkovich MM, Karchevsky KS, (2013) Plasmapheresis in the treatment of patients having interstitial lung diseases. Efferent Therapy 19: $62-63$. 


\section{Hit}

Journal of Anesthesia \& Clinical Care

Journal of Addiction \& Addictive Disorders

Advances in Microbiology Research

Advances in Industrial Biotechnology

Journal of Agronomy \& Agricultural Science

Journal of AIDS Clinical Research \& STDs

Journal of Alcoholism, Drug Abuse \& Substance Dependence

Journal of Allergy Disorders \& Therapy

Journal of Alternative, Complementary \& Integrative Medicine

Journal of Alzheimer's \& Neurodegenerative Diseases

Journal of Angiology \& Vascular Surgery

Journal of Animal Research \& Veterinary Science

Archives of Zoological Studies

Archives of Urology

Journal of Atmospheric \& Earth-Sciences

Journal of Aquaculture \& Fisheries

Journal of Biotech Research \& Biochemistry

Journal of Brain \& Neuroscience Research

Journal of Cancer Biology \& Treatment

Journal of Cardiology: Study \& Research

Journal of Cell Biology \& Cell Metabolism

Journal of Clinical Dermatology \& Therapy

Journal of Clinical Immunology \& Immunotherapy

Journal of Clinical Studies \& Medical Case Reports

Journal of Community Medicine \& Public Health Care

Current Trends: Medical \& Biological Engineering

Journal of Cytology \& Tissue Biology

Journal of Dentistry: Oral Health \& Cosmesis

Journal of Diabetes \& Metabolic Disorders

Journal of Dairy Research \& Technology

Journal of Emergency Medicine Trauma \& Surgical Care

Journal of Environmental Science: Current Research

Journal of Food Science \& Nutrition

Journal of Forensic, Legal \& Investigative Sciences

Journal of Gastroenterology \& Hepatology Research

Journal of Gerontology \& Geriatric Medicine
Journal of Genetics \& Genomic Sciences

Journal of Hematology, Blood Transfusion \& Disorders

Journal of Human Endocrinology

Journal of Hospice \& Palliative Medical Care

Journal of Internal Medicine \& Primary Healthcare

Journal of Infectious \& Non Infectious Diseases

Journal of Light \& Laser: Current Trends

Journal of Modern Chemical Sciences

Journal of Medicine: Study \& Research

Journal of Nanotechnology: Nanomedicine \& Nanobiotechnology

Journal of Neonatology \& Clinical Pediatrics

Journal of Nephrology \& Renal Therapy

Journal of Non Invasive Vascular Investigation

Journal of Nuclear Medicine, Radiology \& Radiation Therapy

Journal of Obesity \& Weight Loss

Journal of Orthopedic Research \& Physiotherapy

Journal of Otolaryngology, Head \& Neck Surgery

Journal of Protein Research \& Bioinformatics

Journal of Pathology Clinical \& Medical Research

Journal of Pharmacology, Pharmaceutics \& Pharmacovigilance

Journal of Physical Medicine, Rehabilitation \& Disabilities

Journal of Plant Science: Current Research

Journal of Psychiatry, Depression \& Anxiety

Journal of Pulmonary Medicine \& Respiratory Research

Journal of Practical \& Professional Nursing

Journal of Reproductive Medicine, Gynaecology \& Obstetrics

Journal of Stem Cells Research, Development \& Therapy

Journal of Surgery: Current Trends \& Innovations

Journal of Toxicology: Current Research

Journal of Translational Science and Research

Trends in Anatomy \& Physiology

Journal of Vaccines Research \& Vaccination

Journal of Virology \& Antivirals

Archives of Surgery and Surgical Education

Sports Medicine and Injury Care Journal

International Journal of Case Reports and Therapeutic Studies 